\title{
SAPEVO-M: A GROUP MULTICRITERIA ORDINAL RANKING METHOD
}

\author{
Carlos Francisco Simões Gomes ${ }^{1 *}$, Marcos dos Santos ${ }^{2}$, \\ Luiz Frederico Horácio de Souza de Barros Teixeira ${ }^{3}$, \\ Adriana Manzolillo Sanseverino ${ }^{4}$ and Mara Regina dos Santos Barcelos ${ }^{5}$
}

Received July 23, 2019 / Accepted August 19, 2020

\begin{abstract}
This paper proposes a new ordinal method to rank alternatives with multiple criteria and decision makers (DMs). This is a decision group ordinal method called SAPEVO-M, an acronym for Simple Aggregation of Preferences Expressed by Ordinal Vectors Group Decision Making. SAPEVO-M method allows for the aggregation of DM preference rankings into a consensus ranking and expresses the DM degrees of importance in the form of a rank order. It was developed for dealing with purely ordinal criteria and it is also applicable to situations in which ordinal and cardinal criteria are intermixed. A free version of the method was made available on the internet.
\end{abstract}

Keywords: multicriteria decision aid, ordinal ranking methods, group multicriteria decision aid, ordinal data, aggregation of preferences.

\section{INTRODUCTION}

The constant changes in the global scenario and the growing competition for markets in all areas require increasingly important decisions for complex problems from decision makers (DMs), usually in a short time, increasing the value of the decision itself (Moshkovich et al., 2012).

Real-world decision problems are rarely based on a single criterion. They generally involve a variety of criteria, often contradictory. In many practical situations, alternatives must be ranked given multiple, conflicting criteria of preference (Silva et al., 2018a). In addition, group decision

\footnotetext{
*Corresponding author

${ }^{1}$ Universidade Federal Fluminense (UFF), Rua Passos da Pátria, 156, Bloco D, São Domingos, Niterói, RJ, Brasil E-mail: cfsg1@bol.com.br - https://orcid.org/0000-0002-6865-0275

2 Instituto Militar de Engenharia (IME), Praça General Tibúrcio, 80, Urca, Rio de Janeiro, RJ, Brasil - E-mail: marcosdossantos_doutorado_uff@yahoo.com.br - http://orcid.org/0000-0003-1533-5535

${ }^{3}$ Centro de Análises de Sistemas Navais (CASNAV), Praça Barão de Ladário S/N, Rua da Ponte, Edifício 23 do AMRJ, Rio de Janeiro, RJ, Brasil - E-mail: frederico.horacio@gmail.com - https://orcid.org/0000-0002-4176-183X

${ }^{4}$ Universidade Federal Fluminense (UFF), Rua Passos da Pátria, 156, Bloco D, São Domingos, Niterói, RJ, Brasil E-mail: adrianams@id.uff.br - http://orcid.org/0000-0002-3101-5171

5 Universidade Federal Fluminense (UFF), Rua Passos da Pátria, 156, Bloco D, São Domingos, Niterói, RJ, Brasil E-mail: marabarceloss@gmail.com - http://orcid.org/0000-0001-6659-6036
} 
making structures can be used with other techniques, such as a stochastic analysis of acceptability of specific groups (Kadziski et al., 2018).

Multicriteria Decision Making (MCDM) has been one of the fastest growing areas of Operational Research (OR) during the last two decades and it is one of the most used decision methodologies in science, business, government and engineering to support the quality of the decision making process (Aires \& Ferreira, 2018).

A difference that distinguishes MCDM from other classic OR techniques is that MCDM is based on rigorous axioms that characterize an individual's choice behavior to consider DM preferences, formalized in the theory of preferences (Almeida et al., 2018).

Multicriteria decision making and analysis methods are applied when there is a need to select, rank, sort or describe the present alternatives in a complex decision making process with multiple criteria and conflicting objectives (Silva et al., 2018). Evaluation and selection are a typical MCDM problem involving multiple criteria that can be both qualitative and quantitative (Zhang D et al., 2009).

The DM needs to take into consideration many different alternatives and conflicting issues (criteria) at the same time. The situation becomes even more challenging when decisions need to be made jointly or negotiated by many DMs, each with their own viewpoints, preferences, aspirations, or reservation levels (Almeida \& Wachowicz, 2017).

However, the elicitation of the parameters of a preference model frequently comprises some arbitrariness, imprecision. This is particularly the case when the entity in charge of the decision is a group, where members usually disagree concerning the parameter values, or when a DM is a mythical person (Fernández et al., 2019). It is held to be essential that the members participate in an interactive procedure which allows a satisfactory result to be reached (Alencar et al., 2010).

In academic literature of Group Decision, studies involving the consensus of multiple DMs are common. If, at first, the meaning of the word consensus was understood in its literary version, when a unanimous and integral agreement was reached between the agents involved; later, in a more flexible and closer to reality way, the researchers started to understand the consensus as a resolution that meets, at least, the majority of the agents involved with some degree of agreement, generally high (Herrera-Viedma et al., 2011).

For Triantaphyllou et al. (2020) extending the second definition, consensus should not even be understood as the end of the process. Thus, for those authors, the analysis after the result would have the potential to infer useful information about DMs and / or the ranking of alternatives.

Contreras et al. (2011) had already explored two different situations. While in the first situation, consensus depends on a general decision of the entire group since there are no chances that the group might split into coalitions that look for more favorable solutions for the coalition members; in the second approach, there is the possibility of coalition formation and the goal is to obtain rankings in which disagreements of all the coalitions are taken into account. However, in both 
ways, the problem is that the lack of basic arrangement can reduce the level of commitment to the project and, consequently, their chances of success (Castellini et al., 2017).

Greco et al. (2012), in turn, search for the spaces of consensus and disagreement between the multiple DMs using the principle of robust ordinal regression, in which preferences of the DMs on a set of alternatives are modeled by the use of the Multi-Attribute Utility Theory (MAUT), in form of different combinations of the necessary and the possible outcomes.

Although problems involving group decisions are common and more realistic for several decision problems, since modern organizations have been prioritizing the formation of small teams to solve everyday situations at the tactical, operational and strategic level, there are few models that consider this approach (Zanazzi et al., 2014; Alencar \& Almeida, 2010).

Nehring \& Pivato (2019) question what is the best view of an impartial and acceptable consensus that satisfies the group's decision when its members disagree.

Different aggregation methods are developed depending on which kind of data is prepared in the first phase. The ranking methods can be placed into two basic categories, namely as cardinal and ordinal methods. Cardinal methods require DMs to express their degree of preference for one alternative over another for each criterion, while ordinal methods require that only the rank order of the alternatives be known for each criterion (Ahn \& Choi, 2012).

In many real-world applications, however, it is essential to consider the existence of ordinal (qualitative) factors when rendering a decision on the performance. In some situations, such as the one described, the data for certain influence factors might be better represented as rank positions in an ordinal, rather than in a numerical sense (Saen, 2007).

This paper presents a compensatory method called SAPEVO-M (Simple Aggregation of Preferences Expressed by Ordinal Vectors Group Decision Making). It is an evolution of SAPEVO (Simple Aggregation of Preferences Expressed by Ordinal Vectors), an ordinal method proposed by Gomes et al. (1997). This new version allows many DMs to express their preferences among the criteria, based on an ordinal analysis that generates weights for each DM and aggregates all weights. SAPEVO-M method also allows an analysis of the intra-criterion alternatives from the same ordinal preference; it generates cardinal values for each DM, aggregates these values and ranks the alternatives in each criterion.

This paper is structured into five sections: section 1 presents the research context and defines the objective of the study. Section 2 reviews multicriteria decision concepts, preference information and ordinal methods. Section 3 explains the method axiomatically. Section 4 provides an illustrative example and discusses the application of SAPEVO-M method. Section 5 concludes the study.

\section{MULTICRITERIA DECISION CONCEPTS}

The MDCM methods plays an important role in the selection of the non-dominant alternatives among several feasible alternatives evaluated according to multiple criteria in real-life decision 
making problems involving uncertainty (Sahin, 2016). The following aspects should be involved in quality decision making (De Souza et al., 2018; De Carvalho et al., 2015):

- A perception of the DM regarding the necessity and appropriateness of the decision, considering marketing, operational, technological, strategic, financial variables, etc.

- The adoption of a methodology or combination of methodologies, enabling the identification of the variables and a rational analysis of the information; and

- The assessment of the necessity and feasibility of sharing the decision making process to ensure the required engagement in the deployment of the chosen alternative.

Multiple criteria decision analysis (MCDA) is a common human activity that helps to make decisions (Zhang W et al., 2017). Among the many approaches that have been designed to support MCDA, three of them stand out (Belton \& Stewart, 2002; Corrente et al., 2012; Corrente, et al., 2016; Greco et al., 2016):

- Choice (Problem P $\alpha$ ) - aims to clarify the decision by choosing a subset that is as restricted as possible, considering the final choice of a single action. This set will contain the "best actions" or the "satisfactory" actions.

- Ranking (Problem $\mathrm{P} \beta$ ) - aims to clarify the decision through a screening resulting from the allocation of each action to a category (or class). The subset of action is that could be sufficiently satisfactory, based on preference model. It suggests a partial or complete order formed by the class containing action.

- Sorting (Problem P $\gamma$ ) - aims to clarify the decision through an arrangement obtained by the regrouping of all or part (the most satisfactory) of the actions in equivalence classes. These classes are ordered, completely or partially, according to preferences.

In addition, Problem $\mathrm{P} \delta$ aims to clarify the decision through a description, in appropriate language, of the actions and their consequences. The desired result is therefore a description or a cognitive procedure. The number of DMs and the nature of the criteria must be considered while solving problems (Zhang D et al., 2009).

- The structuring of the model is fundamental in a decision support process, which is both a science and an art (Cardoso, Xavier, Gomes \& Adissi, 2009). The process has (Keeney and Raiffa, 1993):

- A set of m action alternatives: $A=\left\{x_{1}, x_{2}, \ldots, x_{m}\right\}$.

- A set of n criteria belonging to a finite set: $g=\left\{g_{1}, g_{2}, \ldots, g_{n}\right\}$.

- A set of m DMs who express their preferences: $D=\left\{D_{1}, D_{2}, \ldots, D_{m}\right\}$.

- A set of criteria weights: $W=\left\{w_{\left(g_{1}\right)}, w_{\left(g_{2}\right)}, \ldots, w_{\left(g_{n}\right)}\right\}$. 
A detailed selection of criteria must be specified to make a perfect decision and this process includes many criteria and requires uncertain evaluations (Oztaysi et al., 2017). The criteria family must satisfy the following consistency conditions (Greco et al., 2008):

- Exhaustive - any two alternatives having the same evaluations on all criteria should be considered indifferent; the criteria family is exhaustive if all relevant aspects of the problem are taken into account.

- Cohesion - imposing correct distinctions of those criteria that are maximizing and thus minimizing (Gomes et al., 2017).

- Monotonicity - when comparing two alternatives, an improvement of one of them on at least one criterion should not deteriorate its comparison to the other alternative.

- Non-redundancy - exclusion of criteria whose value characteristics are already provided by other criteria; or, deletion of any criterion will contradict one of the above conditions.

The decision making process largely consists of two phases: (1) construction of a decision making problem and data preparation; (2) aggregation and exploitation (Greco et al., 2011).

MCDA faces three important methodological challenges: handling a complex structure of criteria, dealing with interactions between criteria, and reducing the cognitive effort of the DMs in the interaction with MCDA methods. These challenges are usually handled separately, but they often concern the same decision problem (Angilella et al., 2016).

In many practical situations, alternatives must be ranked given multiple and conflicting criteria. The set of criteria can comprise quantitative as well as qualitative criteria (Gomes et al., 1997). Compared to selection or choice problems, solving ranking problems can be more difficult and complex, requiring the DM to have more information available (Frej, Almeida \& Costa, 2019). So, when experts, who, like all human beings, sometimes make mistakes, make pairwise comparisons, the phenomenon of inconsistency emerges naturally. The ranking synthesis algorithm must take this into account (Kulakowski, 2018).

Among many approaches that have been designed to support MCDA, three of them seem to prevail (Greco et al., 2011):

- The first one exploits the idea of assigning a score to each alternative, as is the case with MAUT;

- The second relies on the principle of pairwise comparison of alternatives, as is the case with outranking methods;

- The third one induces logical if, then decision rules from decision examples;

The DM provides some holistic preferences on a set of reference alternatives $A_{0} \rightarrow A^{R}$, and the parameters of the decision model are induced from this information using a methodology called ordinal regression. 
Subsequently, a consistent aggregation model is taken into consideration to evaluate the alternatives from set $A$ (aggregation approach). Typically, ordinal regression has been applied to MAUT models, such that in these cases we speak of additive ordinal regression. For example, the wellknown multicriteria method UTA is mainly based on the additive ordinal regression. The principles of ordinal regression have also been applied to some non-additive decision models. In this case, we speak of non-additive ordinal regression and, in this context, we can think of some UTA like-methods within the Choquet integral framework. Ordinal regression has also been applied to outranking methods and, particularly to ELECTRE and PROMETHEE (Angilella et al., 2010, 2016).

Outranking relation, usually denoted by $S$, was proposed by Bernard Roy, whose aim was to establish a realistic representation of four basic situations. The usefulness of the outranking model comes from the fact that it is based on relatively weak mathematical assumptions. It attempts to enrich the dominance relation by strongly established preferences, accepting incomparability and neither imposing completeness nor transitivity of preference: indifference, weak preference, strict preference, and incomparability. The preference model in the form of an outranking relation is most widely used in the ELECTRE family of MCDA methods. This is not an easy task for a $\mathrm{DM}$, because it requires establishing a precise numerical value for such parameters as the importance coefficients (weights) of criteria, indifference, preference, and veto thresholds. Moreover, some technical parameters need to be established in advance, like the concordance threshold and distillation parameters (Greco et al., 2011).

A DM will rank the alternatives in $A$ from best to worst according to his/her preferences. Alternatives must be partially or totally rank ordered from best to worst, while in sorting problems each alternative should be assigned to one or more contiguous, preferentially-ordered classes. To deal with any of these problems, the evaluations of the alternatives regarding the considered criteria must be aggregated by a preference model, which can be either a value function or an outranking relation (Angilella et al., 2016).

The ranking of alternatives from set $A$ results from the ordering of indifference classes of $A$, which group alternatives deemed as indifferent. In the partial ranking, some indifference classes may remain incomparable. The construction of a ranking using a MCDA method requires analysis of two types of information: weak dominance relation and preference information provided by the DM (Kadziski et al., 2012). Chakhar et al. (2016) proposed a three-phase approach to support classification in groups of DMs, using dominance.

In multicriteria ranking problems, alternatives are compared pairwise, and the results express preferences with the use of comparative notions. Despite the many differences between ordinal and cardinal pairwise comparisons, both approaches have much in common. Both approaches use the idea of inconsistency among individual comparisons. The notion of inconsistency introduced by the pairwise comparisons method is based on the natural expectation that every two comparisons of any three different alternatives should determine the third possible comparison among those alternatives (Kulakowski, 2018). 
The value function, the outranking relation and the set of decision rules are three preference models underlying these three main approaches. It is known that the DM should provide some preference information to build such models. A relatively little-discussed decision making problem is that of aggregating multi DM preference rankings into a consensus ranking, in the specific case in which the DM importance is expressed as a rank-ordering. This specific problem is classified as ordinal semi-democratic (Franceschini \& Maisano, 2015).

\subsection{Preference information}

At the input, the DM is asked to provide the following preference information (Angilella et al., 2016):

- Comparisons related to the importance and interaction of macro-criteria (group of criteria considered in the multiple criteria hierarchy process) as well as between some elementary criteria (criterion in a macro criteria), not necessarily belonging to the same macro-criterion;

- Preference comparisons between alternatives at a comprehensive level as well as considering only a macro-criterion and, therefore, a particular aspect of the problem at hand.

Tang et al. (2019) state that in group decision making problems, considering the complexity of the problematic situation, as well as human cognition, it is to be expected that there are different ways of expressing the information of preference.

The preference information provided by a DM may be numerical values, such as exact values, interval values and fuzzy numbers. Under many conditions, the classical approaches are not conducive to overcome the difficulties in the processing of this information (Sahin, 2016).

The preference information may be either direct or indirect, depending on whether it directly specifies values of some parameters used in the preference model (e.g. trade-off weights, aspiration levels, discrimination thresholds, etc.), or specifies some holistic judgments from which compatible values of the preference model parameters are induced (Greco, Mousseau \& Sowinski, 2008; Greco, Kadziski, Mousseau \& Sowinski, 2011; Kadziski, Greco \& Sowiski, 2012).

Direct preference information is used in the traditional aggregation paradigm, according to which the aggregation model is first constructed and then applied to set A to rank the alternatives. Eliciting direct preference information from the DM can be counterproductive in real-world decision making because of the high cognitive effort required. Consequently, directly asking the DM to provide values for the parameters may make the DM uncomfortable. Eliciting indirect preference is less demanding of the cognitive effort (Greco et al., 2008, 2011; Kadziski et al., 2012).

Indirect preference information is used in the disaggregation (or regression) paradigm, according to which the holistic preferences on a subset of alternatives $A^{R} \in A$ are known first, and then a 
consistent aggregation model is inferred from this information to be applied on set $\mathrm{A}$ in order to rank the alternatives. The parameters are inferred, not the aggregation model. The aggregation model needs to be assumed at the beginning. MCDA methods based on indirect preference information and on the disaggregation paradigm are considered more interesting, because they require an easy cognitive interpretation for the DM to express some preference information. Indirect preference information is mainly used in the ordinal regression paradigm. According to this paradigm, holistic preference information on a subset of some reference or training alternatives is known first and then a preference model compatible with the information is built and applied to the whole set of alternatives to arrive at a ranking, choice, or sorting recommendation (Greco et al., 2011).

Srdjevic B \& Srdjevic Z. (2013) mention several methods for obtaining weights, as additive normalization (AN), eigenvector (EV), logarithmic least squares (LLS), weighted logarithmic least square (WLS), logarithmic goal programming (LGP) and fuzzy preference programming (FPP). The authors applied the EV method in their research, which generates a priority vector, considering it a competitive and widely used method. Srdjevic B \& Srdjevic Z. (2011) proposed an analytic hierarchy process (AHP) in group contexts and developed an algorithm called multicriteria group prioritization synthesis (MGPS), which considers the best vectors in the final synthesis to obtain the best possible consistency.

Sometimes the mutual preference independence can be violated. For example, in an excellent (comfortable) car with high speed, the price may be associated with comfort and high speed (Corrente et al., 2016).

Angilella et al. (2010) consider another point regarding mutual preference independence. For them, the comprehensive importance of criteria is greater than the sum of the importance of two or more criteria considered separately. They propose that in the same decision problem, there is very often a positive interaction (synergy) of criteria instead of a mutual preference independence problem.

\subsection{Ordinal Methods}

Ordinal methods were the first methods to be developed after the mid-18th century through the studies of Jean Charles Borda. In these methods, $m$ alternatives and $n$ criteria are listed, generating an ordinal ranking from best to worst alternative at the end. Borda (De Borda, 1781), Condorcet (Condorcet, 1788) and Copeland (Copeland, 1951) methods are the most familiar.

These ordinal methods have been widely explored in the literature, with researchers discussing their vulnerabilities, such as the Condorcet paradox when the voting situation becomes cyclical and it is not possible to establish a ranking. In this case, the Borda and Coopeland methods are usually used because they are considered more reliable. However, Favardin et al. (2002) explores the weakness, especially of the Borda and Copeland methods, regarding their strategic manipulation, in problems of voting ordinals, suggesting that the Coopeland method is slightly less suggestive of this type of error. 
As attribute weights are usually the hardest parameters to elicit in MCDM problems, works in the literature have mainly centred on the case in which the information regarding weights is imprecise, which is often represented by ordinal information (Aguayo et al., 2014).

Sarabando et al. (2016) presented a structure for group decision making, when individual preferences are not exact. Ordinal information was used to classify the weight of attributes, alternative values, and differences in values between consecutive alternatives for each attribute. The authors used a Monte-Carlo simulation to approximate the relative volume of the parameter space domain in each condition maintained, with respect to the domain of the values of viable variables. Therefore, alternatives with an extremely low (zero) probability of being optimal can be discarded. In addition, the approach allows to identify dominate alternatives, without solving complex optimization problems.

Recent studies show that ordinal methods are still in use. Pereira et al. (2018) applied ordinal methods to choose an ERP system for a retail company. Teixeira MLR et al. (2018) used the Copeland method in the bidding for life insurance at a public education institution. Guimarães et al. (2019) used the Borda and Copeland methods to compare the economic development policies of South Korea and Chile.

However, these ordinal methods provide a ranking without a scalar measure for each alternative. Many methods accounting for ordinal information on weights and alternative values / utilities within MAUT can be found in the literature; however, the ranking of the difference between the values of consecutive alternatives used to represent DM preferences is not so commonplace in the literature (Aguayo et al., 2014).

This limitation was overcome, with restrictions by the SAPEVO method, proposed by Gomes et al. (1997). This paper is an update of SAPEVO.

\section{SAPEVO-M METHOD}

This paper proposes to extend the method developed by Gomes et al. (1997) to group decision, in addition to checking its consistency in the matrix normalization process.

The original model could generate negative weights if there was no pre-ordering of the criteria to be compared in Step 2 and 3. This requirement of ordering the criteria in order of preference prevents the use of multiple DMs, because everyone will have to agree on the order of preference of the criteria. The correction of these problems allowed for the use of the method with multiple DMs.

SAPEVO-M method transforms the ordinal preferences of criteria into a vector of criteria weights (Steps 1 and 2); integrates the vector criteria of different DMs (Step 3); transforms the ordinal preferences of alternatives for a given set of ranking criteria into a partial weight of alternatives (Steps 4, 5 and 6); determines the global preferences of alternatives (Steps 7, 8 and 9). The preference information is provided in the form of a set of pairwise comparisons of some alternatives. Figure 1 shows the steps of SAPEVO-M method: 


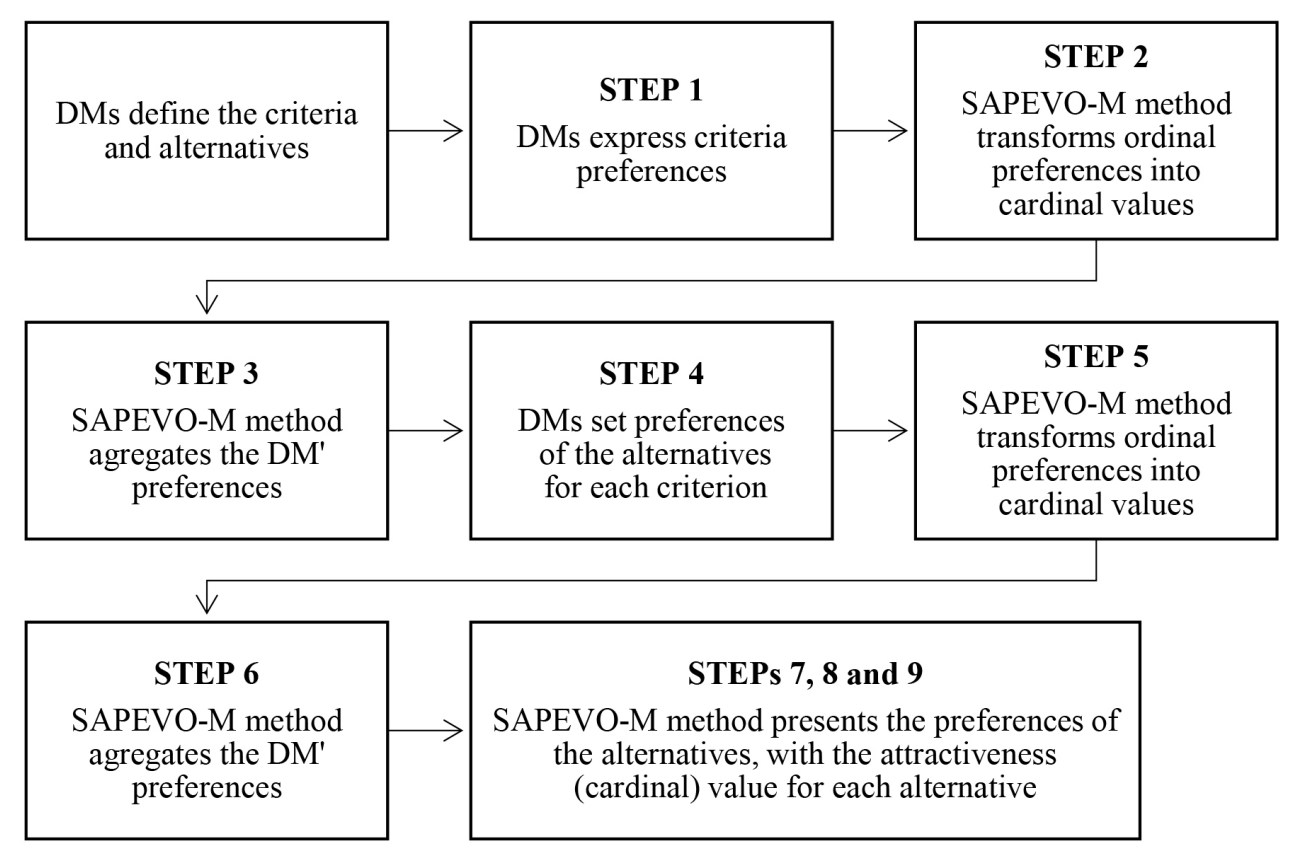

Figure 1 - The steps of SAPEVO-M method.

Given a set of alternatives and a set of criteria $i, j$, both defined by DMs, SAPEVO-M method starts at step 1 to establish criteria preferences, considering general elements $\left(\delta_{i j}\right)$, such that: $\delta_{i j}=1 \leftrightarrow i \cong j, \delta_{i j}>1 \leftrightarrow i>j, \delta_{i j}<1 \leftrightarrow i<j$. Where: $\cong$ is as important as, $>$ is more important than, and $<$ is less important than.

In step 2, SAPEVO-M method uses a scale to represent the criteria preferences, according to the relationship (Table 1).

Table 1 - Relationship and scale.

\begin{tabular}{rr}
\hline Relationship & Scale \\
\hline$\ll 1$ & -3 \\
$\preccurlyeq 1$ & -2 \\
$\prec 1$ & -1 \\
1 & 0 \\
$\succ 1$ & 1 \\
$\succcurlyeq 1$ & 2 \\
$\gg 1$ & 3 \\
\hline
\end{tabular}


In step 3, SAPEVO-M method aggregates the preferences. This scale enables a transformation of the matrix $\mathrm{DM}_{\mathrm{k}}=\left[\delta_{\mathrm{ij}}\right]$ into a column vector $\left[\mathrm{v}_{\mathrm{i}}\right]$ such that (equation 1 ):

$$
\sum_{j=1}^{m} \text { (readind Scale } 2 \text { for } \mathrm{i}=1, \ldots, \text { mand } k=1, \ldots, n
$$

Where, $\mathrm{k}$ is the number of decision makers.

Starting from step 4, the SAPEVO-M method transforms the ordinal preferences of the alternatives for a given set of ranking criteria into partial weights of the alternatives.

In step 4, the alternatives are compared pairwise to each criterion, which results in a matrix $\left(E_{i}\right)$.

Given a set of alternatives ( $\mathrm{k}, \mathrm{l}$, and $\mathrm{j}$ ), according to the model of inconsistency (Kulakowski, 2018), if $\mathrm{k} \cong l$, and $j>\mathrm{k}$, there is an inconsistency if $l>j$.

Step 5 is the same as step 2 (scale to represent preference) and step 6 is the same as step 3 (preference aggregation).

In step 7, SAPEVO-M method calculates global preferences. Vector V represent de alternative preferences of each DM. It allows for the transformation of the matrix $E_{i}=\left[e_{i, k, l}\right]$ into a column vector $A_{i}$ where $e_{i, k, l}$ is the value of the pairwise comparison of $a_{k}$ with alternative $a_{l}$ under criterion (i) for each DM.

In step 8, SAPEVO-M method stores the column vector $A=\Sigma A_{D M}$ of the matrix $M_{(n \times m)}$.

In step 9, it changes the criterion (i) and return to step 4 to step 8 until the matrix $\mathrm{M}$ is filled.

\section{NUMERICAL EXAMPLE}

Use Table 1 for conversion.

- Step 1 - Set of criteria, ordinal preferences for each DM (Table 2).

Table 2 - DMs Ordinal preferences.

\begin{tabular}{crrrr}
\hline criterion & $\mathrm{c}_{1}$ & $\mathrm{c}_{2}$ & $\mathrm{c}_{3}$ & $\mathrm{DM}$ \\
\hline $\mathrm{c}_{11}$ & 1 & $\prec 1$ & $\preccurlyeq 1$ & \\
$\mathrm{c}_{21}$ & $\succ 1$ & 1 & $\prec 1$ & $D M_{1}$ \\
$\mathrm{c}_{31}$ & $\preccurlyeq 1$ & $\succ 1$ & 1 & \\
\hline $\mathrm{c}_{12}$ & 1 & $\succ 1$ & $\prec 1$ & \\
$\mathrm{c}_{22}$ & $\prec 1$ & 1 & $\preccurlyeq 1$ & $D M_{2}$ \\
$\mathrm{c}_{32}$ & $\succ 1$ & $\preccurlyeq 1$ & 1 & \\
\hline $\mathrm{c}_{13}$ & 1 & $\prec 1$ & $\prec 1$ & \\
$\mathrm{c}_{23}$ & $\succ 1$ & 1 & $\prec 1$ & $D M_{3}$ \\
$\mathrm{c}_{33}$ & $\succ 1$ & $\succ 1$ & 1 & \\
\hline
\end{tabular}


- Step 2 and Step 3 the ordinal preference of each DM is converted into an individual matrix. Subsequently, it is transformed into a vector. The vector has normalized values.

\section{Matrix $D M_{1}$}

$$
\left|\begin{array}{ccc}
0 & -1 & 2 \\
1 & 0 & -1 \\
-2 & 1 & 0
\end{array}\right|
$$

Vector $D M_{1}\left(V D M_{1}\right)$

$$
V D M 1=\begin{gathered}
1 \\
0 \\
-1
\end{gathered}
$$

Comments: The decision making process proposed by the model requires that a standardization is used. A study with the procedures is presented in Table 3 (Gomes \& Gomes, 2019).

Table 3 - Standardization.

\begin{tabular}{ccl}
\hline Procedure & Formula & Result \\
\hline 1 & $\mathrm{~A}_{\mathrm{ij}} / \operatorname{maxa}_{1 \mathrm{j}}$ & $\begin{array}{l}\text { Generates negative weights; assigns zero weight to the } \\
\text { criterion that is in the middle of the preferences. } \\
\text { Generates positive weights; assigning zero weight to the least } \\
\text { preferred criterion. } \\
\text { Denominator assumes zero value. } \\
\text { Generates negative values for weights, as well as zero value for } \\
\text { the criterion in the middle of the set of preferences. }\end{array}$ \\
\hline
\end{tabular}

Comments: Procedure 2 was adopted. If all DMs attribute less preference to the same criterion, it will have zero weight and will be eliminated from the decision making process. The authors of the article propose the use of zero value for weight instead; $1 \%$ is used for the weight of the next criterion (penultimate least preferred).

Vector $\mathrm{DM}_{1}$ Normalized $\left(\mathrm{VDM}_{1}\right)$

$$
\begin{gathered}
1 \\
0,5 \\
0,005
\end{gathered}
$$

Matrix $\mathrm{DM}_{2}$

$$
\left|\begin{array}{ccc}
0 & 1 & -1 \\
-1 & 0 & -2 \\
1 & 2 & 0
\end{array}\right|
$$

Vector $\mathrm{DM}_{2}\left(\mathrm{VDM}_{2}\right)$

$$
V D M_{2}=-3
$$


Vector $\mathrm{DM}_{2}$ Normalized $\left(\mathrm{VDM}_{2}\right)$

$$
\begin{gathered}
0,5 \\
0,005 \\
1
\end{gathered}
$$

Matrix $\mathrm{DM}_{3}$

$$
\left|\begin{array}{ccc}
0 & -1 & -1 \\
1 & 0 & -1 \\
1 & 1 & 0
\end{array}\right|
$$

Vector $\mathrm{DM}_{3}\left(\mathrm{VDM}_{3}\right)$

$$
V D M 3=\begin{gathered}
-2 \\
0 \\
2
\end{gathered}
$$

Vector $\mathrm{DM}_{3}$ Normalized $\left(\mathrm{VDM}_{3}\right)$

$$
\begin{gathered}
0,005 \\
0,5 \\
1
\end{gathered}
$$

The weights of the criteria after integrated analysis of the DMs are presented in Table 4.

Table 4 - Weights of the criteria.

\begin{tabular}{ccccc}
\hline criterion & $V D M_{1}$ & $V D M_{2}$ & $V D M_{3}$ & Sum (weights) \\
\hline $\mathrm{c}_{11}$ & 1 & 0,5 & 0,005 & 1,505 \\
$\mathrm{c}_{21}$ & 0,5 & 0,005 & 0,5 & 1,005 \\
$\mathrm{c}_{31}$ & 0,005 & 1 & 1 & 2,005 \\
\hline
\end{tabular}

Comments: The steps of the method to establish weights in an ordinal manner can be applied in other ordinal or cardinal methods for the establishment of the weights of the criteria for one or more DMs.

- Step 4

Table 5 expresses the ordinal preferences for each alternative $a_{n}$, for each criterion $c_{j}$ for each decision maker $D M_{k}$. 
Table 5 - Ordinal preferences.

\begin{tabular}{|c|c|c|c|c|c|}
\hline criteria & & $a_{1}$ & $a_{2}$ & $\mathrm{a}_{3}$ & $\mathrm{DM}$ \\
\hline \multirow{3}{*}{$\mathrm{c}_{1}$} & $a_{1}$ & 1 & $\prec 1$ & $\prec 1$ & \multirow{9}{*}{$\mathrm{DM}_{1}$} \\
\hline & $a_{2}$ & $\succ 1$ & 1 & 1 & \\
\hline & $a_{3}$ & $\succ 1$ & 1 & 1 & \\
\hline \multirow{3}{*}{$c_{2}$} & $a_{1}$ & 1 & $\prec 1$ & $\preccurlyeq 1$ & \\
\hline & $a_{2}$ & $\succ 1$ & 1 & $\prec 1$ & \\
\hline & $a_{3}$ & $\preccurlyeq 1$ & $\succ 1$ & 1 & \\
\hline \multirow{3}{*}{$c_{3}$} & $\mathrm{a}_{1}$ & 1 & $\succ 1$ & $\prec 1$ & \\
\hline & $a_{2}$ & $\prec 1$ & 1 & $\preccurlyeq 1$ & \\
\hline & $a_{3}$ & $\succ 1$ & $\preccurlyeq 1$ & 1 & \\
\hline \multirow{3}{*}{$\mathrm{c}_{1}$} & $a_{1}$ & 1 & $\prec 1$ & $\prec 1$ & \multirow{9}{*}{$\mathrm{DM}_{2}$} \\
\hline & $a_{2}$ & $\succ 1$ & 1 & $\prec 1$ & \\
\hline & $a_{3}$ & $\succ 1$ & $\succ 1$ & 1 & \\
\hline \multirow{3}{*}{$c_{2}$} & $a_{1}$ & 1 & 1 & 1 & \\
\hline & $a_{2}$ & 1 & 1 & 1 & \\
\hline & $a_{3}$ & 1 & 1 & 1 & \\
\hline \multirow{3}{*}{$c_{3}$} & $a_{1}$ & 1 & $\prec 1$ & $\prec 1$ & \\
\hline & $a_{2}$ & $\succ 1$ & 1 & $\prec 1$ & \\
\hline & $a_{3}$ & $\succ 1$ & $\succ 1$ & 1 & \\
\hline \multirow{3}{*}{$c_{1}$} & $a_{1}$ & 1 & $\succ 1$ & $\prec 1$ & \multirow{9}{*}{$\mathrm{DM}_{3}$} \\
\hline & $a_{2}$ & $\prec 1$ & 1 & $\preccurlyeq 1$ & \\
\hline & $a_{3}$ & $\succ 1$ & $\preccurlyeq 1$ & 1 & \\
\hline \multirow{3}{*}{$c_{2}$} & $a_{1}$ & 1 & $\prec 1$ & $\preccurlyeq 1$ & \\
\hline & $\mathrm{a}_{2}$ & $\prec 1$ & 1 & $\prec 1$ & \\
\hline & $a_{3}$ & $\preccurlyeq 1$ & $\succ 1$ & 1 & \\
\hline \multirow{3}{*}{$c_{3}$} & $a_{1}$ & 1 & 1 & 1 & \\
\hline & $a_{2}$ & 1 & 1 & 1 & \\
\hline & $a_{3}$ & 1 & 1 & 1 & \\
\hline
\end{tabular}

- Step 5 and step 6 like in steps 2 and 3, the preferences generate a matrix that later generates a vector that is also normalized.

Matrix alternatives, criterion $\mathrm{c}_{1}, \mathrm{DM}_{1}$

$$
\left|\begin{array}{ccc}
0 & -1 & -1 \\
1 & 0 & 0 \\
1 & 0 & 0
\end{array}\right|
$$


Vector $\mathrm{DM}_{1} \mathrm{c}_{1}$

$$
D M_{1} c_{1}=\begin{gathered}
-2 \\
1 \\
1
\end{gathered}
$$

Matrix alternatives, criterion $\mathrm{c}_{2}, \mathrm{DM}_{1}$

$$
\left|\begin{array}{ccc}
0 & -1 & 2 \\
1 & 0 & -1 \\
-2 & 1 & 0
\end{array}\right|
$$

Vector $\mathrm{DM}_{1} \mathrm{c}_{2}$

$$
\begin{aligned}
D M 1 c 2= & 0 \\
& -1
\end{aligned}
$$

Matrix alternatives, criterion $\mathrm{c}_{3}, \mathrm{DM}_{1}$

$$
\left|\begin{array}{ccc}
0 & 1 & -1 \\
-1 & 0 & -2 \\
1 & 2 & 0
\end{array}\right|
$$

Vector $\mathrm{DM}_{1} \mathrm{c}_{3}$

$$
\begin{gathered}
0 \\
D M_{1} c_{3}=-3 \\
3
\end{gathered}
$$

Matrix alternatives, criterion $\mathrm{c}_{1}, \mathrm{DM}_{2}$

$$
\left|\begin{array}{ccc}
0 & -1 & -1 \\
1 & 0 & -1 \\
1 & 1 & 0
\end{array}\right|
$$

Vector $\mathrm{DM}_{2} \mathrm{c}_{1}$

$$
\begin{aligned}
& D M_{2} c_{1}= 0 \\
& 2
\end{aligned}
$$

Matrix alternatives, criterion $\mathrm{c}_{2}, \mathrm{DM}_{2}$

$$
\left|\begin{array}{lll}
0 & 0 & 0 \\
0 & 0 & 0 \\
0 & 0 & 0
\end{array}\right|
$$

Vector $\mathrm{DM}_{2} \mathrm{c}_{2}$

$$
\begin{array}{r}
D M 2 c 2=0 \\
0
\end{array}
$$


Matrix alternatives, criterion $\mathrm{c}_{3}, \mathrm{DM}_{2}$

$$
\left|\begin{array}{ccc}
0 & -1 & -1 \\
1 & 0 & -1 \\
1 & 1 & 0
\end{array}\right|
$$

Vector $\mathrm{DM}_{2} \mathrm{c}_{3}$

$$
D M 2 c 3=\begin{gathered}
-2 \\
2
\end{gathered}
$$

Matrix alternatives, criterion $\mathrm{c}_{1}, \mathrm{DM}_{3}$

$$
\left|\begin{array}{ccc}
0 & 1 & -1 \\
-1 & 0 & -2 \\
1 & 2 & 0
\end{array}\right|
$$

Vector $\mathrm{DM}_{3} \mathrm{c}_{1}$

$$
D M 3 c 1=\begin{gathered}
0 \\
-3 \\
3
\end{gathered}
$$

Matrix alternatives, criterion c2, DM3

$$
\left|\begin{array}{ccc}
0 & -1 & 2 \\
1 & 0 & -1 \\
-2 & 1 & 0
\end{array}\right|
$$

Vector $\mathrm{DM}_{3} \mathrm{c}_{2}$

$$
D M 3 c 2=\begin{gathered}
1 \\
-1
\end{gathered}
$$

Matrix alternatives, criterion $\mathrm{c}_{3}, \mathrm{DM}_{3}$

$$
\left|\begin{array}{lll}
0 & 0 & 0 \\
0 & 0 & 0 \\
0 & 0 & 0
\end{array}\right|
$$

Vector $\mathrm{DM}_{3} \mathrm{c}_{3}$

$$
\begin{array}{r}
D M 3 c 3=0 \\
0
\end{array}
$$


- Step 7

Table 6 shows the vectors obtained (consolidated) in the previous step.

Table 6 - Vectors.

\begin{tabular}{cccccccccc}
\hline & $\mathrm{DM}_{1} \mathrm{c}_{1}$ & $\mathrm{DM}_{1} \mathrm{c}_{2}$ & $\mathrm{DM}_{1} \mathrm{c}_{3}$ & $\mathrm{DM}_{2} \mathrm{c}_{1}$ & $\mathrm{DM}_{2} \mathrm{c}_{2}$ & $\mathrm{DM}_{2} \mathrm{c}_{3}$ & $\mathrm{DM}_{3} \mathrm{c}_{1}$ & $\mathrm{DM}_{3} \mathrm{c}_{2}$ & $\mathrm{DM}_{3} \mathrm{c}_{3}$ \\
\hline $\mathrm{a}_{1}$ & -2 & 1 & 0 & -2 & 0 & -2 & 0 & 1 & 0 \\
$\mathrm{a}_{2}$ & 1 & 0 & -3 & 0 & 0 & 0 & -3 & 0 & 0 \\
$\mathrm{a}_{3}$ & 1 & -1 & 3 & 2 & 0 & 2 & 3 & -1 & 0 \\
\hline
\end{tabular}

Table 7 shows the normalized values of table 6 .

Table 7 - Vectors normalized.

\begin{tabular}{cccccccccc}
\hline & $\mathrm{DM}_{1} \mathrm{c}_{1}$ & $\mathrm{DM}_{1} \mathrm{c}_{2}$ & $\mathrm{DM}_{1} \mathrm{c}_{3}$ & $\mathrm{DM}_{2} \mathrm{c}_{1}$ & $\mathrm{DM}_{2} \mathrm{c}_{2}$ & $\mathrm{DM}_{2} \mathrm{c}_{3}$ & $\mathrm{DM}_{3} \mathrm{c}_{1}$ & $\mathrm{DM}_{3} \mathrm{c}_{2}$ & $\mathrm{DM}_{3} \mathrm{c}_{3}$ \\
\hline $\mathrm{a}_{1}$ & 0 & 1 & 0,5 & 0 & 0 & 0 & 0,5 & 1 & 0 \\
$\mathrm{a}_{2}$ & 1 & 0,5 & 0 & 0,5 & 0 & 0,5 & 0 & 0,5 & 0 \\
$\mathrm{a}_{3}$ & 1 & 0 & 1 & 1 & 0 & 1 & 1 & 0 & 0 \\
\hline
\end{tabular}

Table 8 presents the values of table 7, consolidated for each alternative/criterion.

Table 8 - Alternative/criterion classification.

\begin{tabular}{cccc}
\hline & $\mathrm{c}_{1}$ & $\mathrm{c}_{2}$ & $\mathrm{c}_{3}$ \\
\hline $\mathrm{a}_{1}$ & 0,5 & 2 & 0,5 \\
$\mathrm{a}_{2}$ & 1,5 & 1 & 0,5 \\
$\mathrm{a}_{3}$ & 3 & 0 & 2 \\
\hline
\end{tabular}

Does the product matrix (Table 8):

$$
\begin{array}{ccc}
0,5 & 2 & 0,5 \\
1,5 & 1 & 0,5 \\
3 & 0 & 2
\end{array}
$$

Vector (weights) obtained (Table 4)

$$
\text { weights }=\begin{array}{r}
1,505 \\
1,005 \\
2,005
\end{array}
$$

Getting the preference vector of the alternatives

$$
\begin{aligned}
& \text { al } 3,765 \\
& \text { preferences }=a 2 \quad 4,265 \\
& \text { a3 } 8,525
\end{aligned}
$$


Soon $\mathrm{a}_{3}$ overcomes $\mathrm{a}_{2}$ that surpasses $\mathrm{a}_{1}$.

Although SAPEVO-M is a simple method, it involves matrix calculations that can become laborious depending on the number of DMs, criteria, and alternatives. This is mainly the case because this technique requires the pairwise comparison of all the elements. In order to facilitate its access and use by researchers, a web program was developed and made available on the http://www.sapevoweb.com/ website through the SapevoWeb platform.

The SapevoWeb software was developed based through a partnership between the technical staff of the Naval Systems Analysis Centre (CASNAV), a research group of the Post-Graduation Program in Production Engineering of the Fluminense Federal University (UFF) and a research group of the Post-Graduate Program in Systems Engineering and Computer Science of the Military Engineering Institute (IME).

In 2019, the SapevoWeb software received the registration from the Brazilian National Institute of Industrial Property (Instituto Nacional de Propriedade Industrial - INPI), under number BR512020000667-1. Figure 2 shows the SapevoWeb homepage:

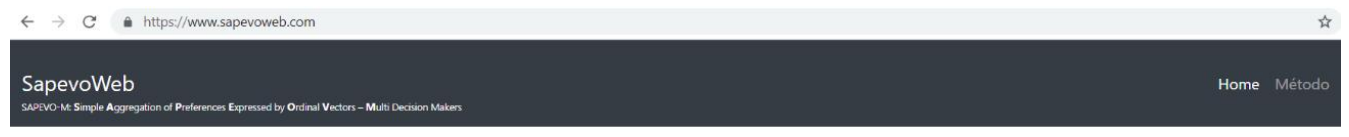

\section{Cadastrar Projeto}

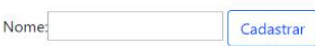

Figure 2 - SapevoWeb homepage (www.sapevoweb.com).

The definition of criteria and alternatives by the DMs must be done before using the SAPEVO-M method. To start using SapevoWeb software, it is necessary to register a project. After that, the DMs, alternatives, and criteria must be included. The evaluation method is done in two steps. In the first step, DMs judge each criterion individually. In the second, they judge the same criteria in pairs. The result is shown at the end of the evaluation.

The implementation of the algorithm allows each DM to present their preferences asynchronously and sequentially. Only one round is required by the DM. The software allows DMs in the same room and asynchronously (one by one). The possibility to the synchronously and different room is a computational (software) implementation.

\section{CONCLUSIONS}

SAPEVO-M method allows for the aggregation of preferences of multiple DMs in an ordinal process. The first part of the method (Step 1 to Step 3) can be used independently by DMs to establish weights to the criteria in an ordinal form. These weights can be later applied in SAPEVO-M or another method (chosen by the DMs). If DMs have a preference vector for the criteria and wish 
to rank alternatives ordinally, they can dispose this vector and use the SAPEVO-M method from step 4 to step 9.

The SAPEVO-M method uses compensatory aggregation. Future studies may consider the development of a non-compensatory model.

\section{ACKNOWLEDGMENTS}

This study was supported, without funding, by the Coordenação de Aperfeiçoamento de Pessoal de Nível Superior - Brazil (CAPES).

\section{References}

[1] Aguayo EA, Mateos A \& Jiménez A. 2014. A new dominance intensity method to deal with ordinal information about a DMs preferences within MAVT. Knowledge-Based Systems, 69:159-169.

[2] AhN BS \& ChOI SH. 2012. Aggregation of ordinal data using ordered weighted averaging operator weights. Annals of Operations Research, 201(1):1-16.

[3] AIRES RFF \& FERREIRA L. 2018. The rank reversal problem in multi-criteria decision making: a literature review. Pesquisa Operacional, 38(2):331-362.

[4] AlENCAR LH \& ALMEIDA AT. 2010. A model for selecting project team members using multicriteria group decision making. Pesquisa Operacional, 30(1):221-236.

[5] Alencar LH, Almeida AT \& Morais DC. 2010.A multicriteria group decision model aggregating the preferences of decision-makers based on electre methods. Pesquisa Operacional, 30(3):687-702.

[6] Almeida AT, GeIger MJ \& Morais DC. 2018. Challenges in multicriteria decision methods. IMA Journal of Management Mathematics, 29:247-252.

[7] Almeida, AT \& Wachowicz T. 2017. Preference Analysis and Decision Support in Negotiations and Group Decisions. Group Decision and Negotiation, 26:649652.

[8] Angilella S, Corrente S, Greco S \& Sowiski R. 2016. Robust ordinal regression and stochastic multiobjective acceptability analysis in multiple criteria hierarchy process for the Choquet integral preference model. Omega, 63:154-169.

[9] Angilella S, Greco S \& Matarazzo B. 2010. Non-additive robust ordinal regression: A multiple criteria decision model based on the Choquet integral. European Journal of Operational Research, 201(1):277-288.

[10] Belton V \& STEWAR T. 2002. Multiple criteria decision analysis: an integrated approach. Springer US. 
[11] Cardoso RS, XAVIER LH, Gomes CFS \& Adissi PJ. 2009. Uso de SAD no apoio à decisão na destinação de resíduos plásticos e gestão de materiais. Pesquisa Operacional, 29(1):67-95.

[12] Castellini MA, Zanazzi JL \& CABRera GP.2017. Selecting working teams for information technology outsourcing projects through a combination of methodologies. Pesquisa Operacional, 37(1): 67-92.

[13] Chakhar S, Ishizaka A, Labib A \& SAad I. 2016. Dominance-based rough set approach for group decisions. European Journal of Operational Research, 251(1):206224.

[14] Condorcet JANC, 1788. Essai sur la constitution et les fonctions des Assemblées provinciales. Paris: LAcadémie des Sciences.

[15] Contreras I, Hinojosa MA \& MŤArmol AM. 2011. Ranking Alternatives in Group Decision-Making with Partial Information: A Stable Approach. Studies in Fuzziness and Soft Computing, 267:41-52.

[16] Copeland AH. 1951. A 'reasonable' social welfare function. Michigan: University of Michigan.

[17] Corrente S, Greco S \& IshizakA, A. 2016. Combining analytical hierarchy process and Choquet integral within non-additive robust ordinal regression. Omega, 61:2-18.

[18] Corrente S, Greco S \& Sowiski, R. 2012. Multiple Criteria Hierarchy Process in Robust Ordinal Regression. Decision Support Systems, 53(3):660-674.

[19] De Borda JC. 1781. Mémoire sur les élections au scrutin. Paris: LAcadémie des Sciences.

[20] De Carvalho Pereira F, Verocai HD, Cordeiro VR., Gomes CFS, \& Costa HG. 2015. Bibliometric analysis of information systems related to innovation. Procedia Computer Science, 55:298-307

[21] De Souza LP, Gomes CFS \& De Barros AP. 2018. Implementation of new hybrid AHP-Topsis-2N method in sorting and prioritizing of an it CAPEX project portfolio. International Journal of Information Technology \& Decision Making, 17(4):977-1005.

[22] Favardin P, Lepelley D \& Serais J. 2002. Borda rule, Copeland method and strategic manipulation. Review of Economic Design, 7:213-228.

[23] Fernández E, Figueira JR \& NAVArro J. 2019. An interval extension of the outranking approach and its application to multiple-criteria ordinal classification. Omega, 84:189-198. 
[24] Franceschini F \& Maisano D. 2015. Checking the consistency of the solution in ordinal semi-democratic decision-making problems. Omega, 57(Part B):188-195.

[25] FREJ EA, AlmeIdA AT \& COSTA APCS. 2019. Using data visualization for ranking alternatives with partial information and interactive tradeoff elicitation. Operational Research, 19:909-931.

[26] Gomes CFS, Costa HG \& DE BARRos AP. 2017. Sensibility analysis of MCDA using prospective in Brazilian energy sector. Journal of Modelling in Management, 12(3):475497.

[27] Gomes, LFAM; Gomes, CFS. 2019. Princípios e métodos para a tomada de decisão: Enfoque multicritério [Principles and methods for decision making: Multicriteria approach]. São Paulo: Atlas.

[28] Gomes LFAM, MURY, AR \& Gomes CFS. 1997. Multicriteria ranking with ordinal data. Systems Analysis Modelling Simulation, 27(2):139-145.

[29] Greco S, Ehrgott M \& Figueira JR. 2016. Multiple criteria decision analysis: state of the art surveys. New York: Springer-Verlag.

[30] Greco S, Kadziski M, Mousseau V \& Sowiski R. 2012. Robust ordinal regression for multiple criteria group decision: UTAGMS-GROUP and UTADISGMS-GROUP. Decision Support Systems, 52:549-561.

[31] Greco S, KAdZISKi M, MousSEAU V \& Sowinski R. 2011.ELECTRE ${ }^{\text {GKMS }}$ : Robust ordinal regression for outranking methods. European Journal of Operational Research, 214:118-135.

[32] Greco S, Mousseau V \& Sowinski R. 2008. Ordinal regression revisited: Multiple criteria ranking using a set of additive value functions. European Journal of Operational Research, 191:416-436.

[33] Guimarães AD, Fona L, Santos M \& Violante AR. 2019. Análise das Políticas de Desenvolvimento Econômico adotadas pela Coreia do Sul e Chile à luz dos métodos de Borda e Copeland [Analysis of the Economic Development Policies adopted by South Korea and Chile in the light of the Borda and Copeland methods]. In: XIX Simpósio de Pesquisa Operacional e Logística da Marinha (SPOLM), Rio de Janeiro, 2019.

[34] Herrera-Viedma E, García-Lapresta Jl, Kacprzy J J, Fedrizzi M, Nurmi H \& ZADrony S. 2011. Consensual Processes. Studies in Fuzziness and Soft Computing, 267:1-10.

[35] Kadziski M, Rocchi L, Miebs G, Grohmann D, Menconi ME \& Paolotti L. 2018. Multiple criteria assessment of insulating materials with a group decision framework incorporating outranking preference model and characteristic class profiles. Group Decision and Negotiation, 27:33-59. 
[36] KADZISKI M, GRECO S \& SOWISKI R. 2012. Extreme ranking analysis in robust ordinal regression. Omega, 40(4):488-501.

[37] KeEney RL, RAIfFA H. 1993. Decision analysis with multiple conflicting objectives preferences and valued tradeoffs. Cambridge: Cambridge University Press.

[38] KULAKOWSKI K. 2018. Inconsistency in the ordinal pairwise comparisons method with and without ties. European Journal of Operations Research, 270:314-327.

[39] Moshrovich HM, Gomes LFA, Mechitov AI \& RAngel LAD. 2012. Influence of models and scales on the ranking of multiattribute alternatives. Pesquisa Operacional, 32(3): 523-542.

[40] Nehring K \& Pivato M. 2019. Majority rule in the absence of a majority. Journal of Economic Theory, 183:213-257.

[41] Oztaysi B, OnAR SC, GozTePe K \& KAHRAmAn C. 2017. Evaluation of research proposals for grant funding usinginterval-valued intuitionistic fuzzy sets. Soft Comput, 21:1203-1218.

[42] Pereira DMS, SAntos M, Reis MF \& WALKer RA. 2018. Ranqueamento e seleção de um sistema ERP para uma empresa do varejo: estruturação e modelagem matemática a partir dos métodos ordinais [Ranking and selection of an ERP system for a retail company: structuring and mathematical modeling based on ordinal methods]. In: Anais do XXV Simpósio de Engenharia de Produção (SIMPEP), Bauru, 2018.

[43] Roy B, Figueira JR. \& Almeida-Dias J. 2014. Discriminating thresholds as a tool to cope with imperfect knowledge in multiple criteria decision aiding: Theoretical results and practical issues. Omega, 43:9-20.

[44] SAEN RF. 2007. Suppliers selection in the presence of both cardinal and ordinal data. European Journal of Operational Research, 183:741-747.

[45] SAHIN R. 2016. Fuzzy multicriteria decision-making method based on the improved accuracy function for interval-valued intuitionistic fuzzy sets. Soft Comput, 20:2557-2563.

[46] Sarabando P, Dias LC \& Vetschera R. 2016. Group decision making with incomplete information: a dominance and quasi-optimality volume-based approach using Monte-Carlo simulation. International Transactions in Operational Research, 26:318-339.

[47] SRDJEVIC B \& SRDJEVIC Z. 2013. Synthesis of individual best local priority vectors in AHP-group decision making. Applied Soft Computing, 13:2045-2056.

[48] Silva MC, Gomes CFS \& Costa Junior, CL. 2018A. A hybrid multicriteria methodology Topsis-Macbeth-2n applied in the ordering of technology transfer offices. Pesquisa Operacional, 38(3):413-439. 
[49] Silva MC, Lima GBA, Gomes CFS, Duncan Rangel LA \& Caiado RGG. 2018B. A SMARTS-Choquets approach for multicriteria decision aid applied to the innovation indexes in sustainability dimensions. Soft Computing, 23(16):7117-7133.

[50] Tang M, Zhou X, liao H, Xu J, Fujita H \& Herrera F. 2019. Ordinal consensus measure with objective threshold for heterogeneous large-scale group decision making. Knowledge-Based Systems. 180:62-74.

[51] Teixeira LFHSB, Santos M \& Gomes CFS. 2018. SapevoWeb Software (v.1).

[52] Teixeira MLR, Reis MF, Santos M, Walker RA \& Lauria RL. 2018. Application of the Copeland method in the life insurance bidding for a public educational institution. Brazilian Journal of Development, 4(5):2522 -531.

[53] Triantaphyllou E, Hou F \& Yanase J. 2020. Analysis of the Final Ranking Decisions Made by Experts After a Consensus has Been Reached in Group Decision Making. Group Decision and Negotiation, 29:271-291.

[54] ZanazZi JL, Gomes LFAM \& DimitrofF M. 2014. Group decision making applied to preventive maintenance systems. Pesquisa Operacional, 34(1):91-105.

[55] Zhang W, JU Y \& LIU X. 2017. Interval-valued intuitionistic fuzzy programming technique for multicriteria group decision making based on Shapley values and incomplete preference information. Soft Comput, 21:5787-5804.

[56] Zhang D, Zhang J, LAI, KK \& LU Y. 2009. A novel approach to supplier selection based on vague sets group decision. Expert Systems with Applications, 36(5):9557-9563.

\section{How to cite}

Gomes CFS, Santos M, Teixeira LFHSb, Sanseverino AM \& Barcelos MrS. 2020. SAPEVO-M: a Group Multicriteria Ordinal Ranking Method. Pesquisa Operacional, 40: e226524. doi: 10.1590/0101-7438.2020.040.00226524. 